\title{
DE ZARZAS TOLEDANAS (CORREA, EL GRECO, MAÍNO)
}

\author{
POR \\ JOSÉ MANUEL CRUZ VALDOVINOS \\ Universidad Complutense
}

\begin{abstract}
The author refutes Richard G. Mann's thesis about the origin in the beato Alonso de Orozco's texts of the burning bramble iconography that appears in the Annunciation Greco's of the Colegio of Doña María de Aragón, and alludes to other examples of the biblical image's use in the toledane painting in relationship with the liturgy. He also remarks that one of the paintings recorded by the Greco was the Incarnation from Tiziano for San Salvador of Venice.
\end{abstract}

Diversos autores se han referido a la zarza ardiendo que el Greco pintó en la Encarnación que ocupaba el centro del retablo mayor de la iglesia del colegio de la Encarnación de Madrid, conocido como de doña María de Aragón por el nombre de su fundadora y que estaba terminado en 1600. La pintura, después de haber pasado un siglo (desde 1883) depositada en el museo de Villanueva y Geltrú, volvió al museo del Prado, donde actualmente se exhibe(Fig. 1 y 3 ).

El escaso, por no decir nulo, conocimiento del dogma católico por parte de algunos autores, especialmente de los de origen norteamericano, y la ignorancia, cuando no desprecio, de la pintura toledana contemporánea del Greco ha llevado a interpretaciones a nuestro juicio erróneas acerca de ese particular elemento.

Sin ánimo de ser exhaustivos señalaremos algunas de las opiniones vertidas sobre el significado de la aparición de la zarza. Para Wethey es símbolo de castidad ${ }^{1}$ y para Álvarez Lopera de pureza ${ }^{2}$. No son exactas estas interpretaciones, pero también es cierto que ambos autores no se ocupan específicamente del asunto. Tampoco se entretiene en ello Pérez Sánchez, aunque afirma con acierto que remite a la zarza de Moisés (Éxodo, 3, 2) y también que es prefiguración de la Redención, lo ya no es tan estricto en esta ocasión ${ }^{3}$. Rosenbaum fue seguido con entusiasmo por Jordan ${ }^{4}$, quien afirma literalmente: «La zarza ardiente ... sin duda alude a la zarza que ardía

\footnotetext{
${ }^{1}$ Harold E. Wethey, El Greco and his School, Princeton, 1962 (Princeton University Press); ed. castellana El Greco y su escuela, Madrid 1967 (Guadarrama), II, n. ${ }^{\circ} 13$.

2 José Álvarez Lopera, El Greco y su escuela, Madrid 1993 (Silex), 184.

3 Alfonso E. Pérez Sánchez, Las series dispersas del Greco en El Greco de Toledo, Madrid, 1982 (Ministerio de Cultura), 162.

${ }_{4}^{4}$ Allen Rosenbaum, Old Master Paintings from the Collection of Baron Thyssen-Bornemisza, Washington, 1979, 150 y William B. Jordan, Catálogo. La Anunciación en El Greco de Toledo, cit., 242.
} 


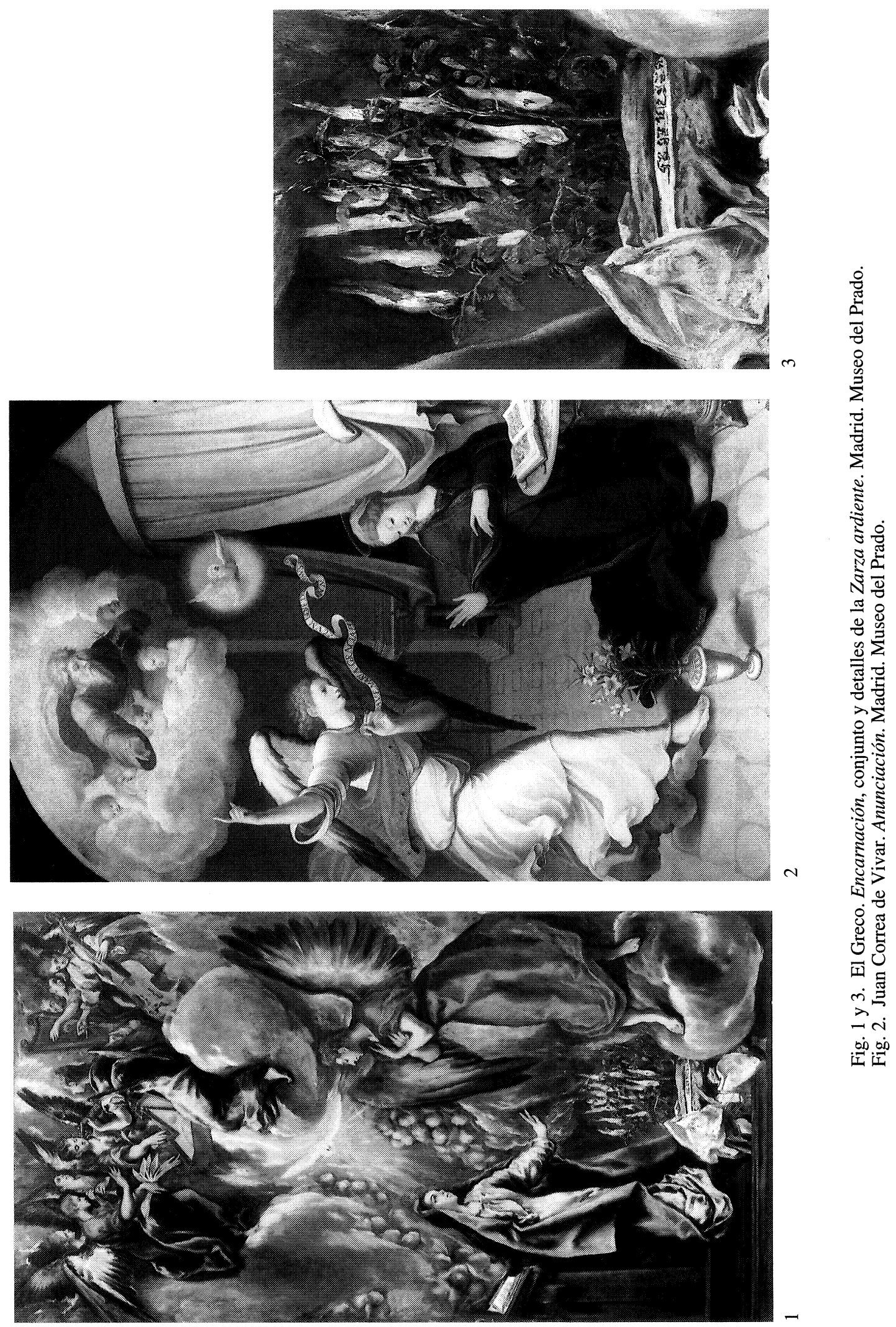


sin consumirse cuando el Señor se apareció a Moisés; análogamente, la Virgen recibió la Divina Luz en el momento de la Concepción pero siguió siendo inmaculada». Por supuesto que atinan los citados autores en la alusión a la zarza en que Yaveh se apareció a Moisés, pero la posterior analogía que establecen es absurda. Cuando se habla de la condición inmaculada de María, el privilegio mariano ha de referirse a la ausencia de pecado en su propia concepción y no a la virginidad intacta antes del parto, en el parto y después del parto. En efecto, María es inmaculada porque fue concebida sin pecado original, por un especial designio de Dios, a diferencia de cualquier otro mortal. La encarnación de Cristo en María por obra del Espíritu nada tiene que ver con la concepción como criatura sin mancha, que es el dogma que se proclama bajo la advocación de la Concepción Inmaculada de María. Pensamos que no ha podido haber un solo intérprete bíblico que relacione la zarza de la historia de Moisés con la concepción sin pecado de María en el seno de su madre, pero sí, como se ve, algunos historiadores del Arte.

Pero el autor que se ha ocupado de manera específica de la zarza en la pintura citada del Greco ha sido Richard G. Mann ${ }^{5}$. La extraordinaria difusión de su interesante libro sobre el cretense no se ha correspondido, parece, con una similar lectura crítica y ya hay ejemplos de aceptación sin reservas de sus afirmaciones acerca del simbolismo de la zarza ${ }^{6}$ y en general de su estudio sobre el cuadro y el retablo completo del Colegio, que es, a nuestro entender, muy discutible.

La tesis fundamental de Mann reside en que la manera de representar los distintos asuntos en las pinturas del retablo depende de los escritos del beato agustino fray Alonso de Orozco (1500-1591) que, al parecer, fue enterrado en la iglesia del Colegio bajo el altar mayor. Hasta tal extremo conduce su argumentación que niega la pertenencia al retablo de la Resurrección y de la Venida del Espíritu Santo (museo del Prado) por las ausencias de ángeles a los que se refería Orozco al comentar tales acontecimientos.

No es nuestro propósito en esta ocasión hacer la crítica y rechazar los argumentos ofrecidos por el estudioso norteamericano. Nos limitaremos a indicar que fray Alonso falleció de muy avanzada edad, dos años antes de que doña María de Aragón regulara en su testamento la fundación del Colegio de agustinos. La iglesia - Mann confunde constantemente colegio y templo- no estaba terminada y de hecho no lo estuvo hasta que en 1600 se colocó el retablo mayor con las pinturas del Greco. Doña María designó como testamentario a don Jerónimo de Chiriboga, canónigo de la colegiata de Talavera de la Reina (y no de Talavera la Vieja, donde no existió colegiata alguna) y miembro del consejo de don Gaspar de Quiroga, cardenal arzobispo de Toledo, de quien también fue testamentario. El retablo fue encargado por los miembros del Consejo Real, pues la institución era de patronato regio, aunque no se ha encontrado la escritura. Pero es lógico pensar que las diversas y notables peculiaridades iconográficas que adornan y enriquecen las pinturas fueron inspiradas por Chiriboga, que sin duda poseía conocimientos teológicos y de Sagrada Escritura suficientes para ello.

${ }^{5}$ Richard G. Mann, El Greco and his Patrons. Three major projects, Cambridge, 1986 (University Press), 79-86; ed. castellana: El Greco y sus patronos. Tres grandes proyectos, Madrid, 1994 (Akal), 76-82; las citas que se hagan corresponden a esta última edición.

${ }^{6}$ Ana Sánchez-Lassa de los Santos, La Anunciación de El Greco en el museo de Bellas Artes de Bilbao y su restauración, «Urtekaria», 1989, 57-74 y en concreto, 62. Más cauto se muestra Álvarez Lopera en la obra citada. Concluido este trabajo se ha celebrado una exposición de la obra en Bilbao y Madrid. En los interesantes textos del correspondiente catálogo no se hace mención de la opinión de Mann ni siquiera por Ana Sánchez-Lassa. El profesor Pita, al ocuparse de cuestiones iconográficas en las distintas versiones de la Anunciación del Greco, sólo entre paréntesis escribe de la zarza: «tal vez alusión a la del Antiguo Testamento en un posible afán del Greco de establecer concordancias con el Nuevo». De modo general, Alvarez Lopera considera que no es convincente la argumentación de Mann sobre el retablo madrileño como ilustración de las visiones místicas del beato Alonso de Orozco. Cfr.: La Anunciación de El Greco. El ciclo del Colegio de María de Aragón, Madrid, 1997 (Museo de Bellas Artes de Bilbao y Museo Thyssen Bornemisza), en especial 29 y 40. 
Mann afirma que el programa iconográfico «se basa con toda seguridad en los escritos de Alonso» y procura justificarlo; también dice que el Greco no estaba muy familiarizado con los escritos del agustino, lo que pensamos que es cierto. Para explicar entonces que el Greco llegara a pintar todos los lienzos siguiendo al pie de la letra los escritos de Orozco, escribe: «Parece ser que Rojas (Hernando de Rojas, rector agustino del Colegio), que fue confesor de Alonso y dirigió la campaña para su canonización, tuvo un importante papel a la hora de determinar el contenido de las pinturas e identificar en los escritos de Alonso los motivos más apropiados para que los ilustrara el artista» ${ }^{7}$. Opinamos que la afirmación es gratuita y el «parece ser» resulta ilustrativo. Mann intenta resaltar el papel de Rojas como agustino y conocedor de los escritos de Orozco, pero no vemos que se justifique documentalmente su influencia y no se le menciona nunca en relación con el retablo.

Pero, además de lo dicho, debemos hacer otra importante afirmación. Las inspiraciones que Mann encuentra en los escritos de Orozco respecto a las pinturas del Greco no son tales, a nuestro entender. Muchas de ellas derivan de aspectos de la doctrina católica común y se encuentran en la Biblia y en los Santos Padres con frecuencia. Dicho autor no entiende en ocasiones lo que el agustino escribió -él mismo afirma una vez que «los escritos del fraile resultan incomprensibles»- y le ha hecho decir lo que nunca dijo. No vamos a ocuparnos aquí de otro asunto que de la zarza ardiendo, pero al menos señalaremos un ejemplo, entre los varios que podrían aducirse, para que el lector advierta mejor lo que estamos afirmando. Escribe Mann: «De acuerdo con la creencia católica tradicional Alonso considera que la Encarnación se producía cada vez que se celebraba la Misa (nota 186). La concepción de Cristo en el vientre de María se repetía cada vez que la Hostia se transformaba en el cuerpo de Cristo al repetir el sacerdote las palabras de aceptación de María «fiat mihi secundum verbum tuum» (Lucas 1: 38) (nota 187). Comparaba Alonso el privilegio de sostener la Hostia con la concepción y protección de Cristo en el vientre de María» ${ }^{8}$. Las notas remiten al Epistolario, 104 v., es decir, al Epistolario christiano para todos los estados, Alcalá de Henares 1567 (Juan de Villanueva). Las citas corresponden a la cuarta epístola, que Orozco dedica a un sacerdote, pero nada de lo que Mann escribe se encuentra en el texto del agustino. Orozco establece allí un paralelo entre la encarnación de Cristo en María y la transubstanciación en el cuerpo y sangre de Cristo que se produce a la consagración de la hostia. Recoge, en efecto, las palabras de aceptación de María y más tarde dice que el sacerdote consagra con aquellas cinco palabras. Pero es claro que esas palabras son la fórmula de la consagración, «hic est enim Corpus meum» y no «fiat mihi secundum verbum tuum» que no se pronuncian nunca en el Canon de la Misa y menos aún en la fórmula consagratoria. La circunstancia de que sean cinco palabras en ambos casos originó el error, imposible para cualquier persona que conozca un poco la teología y liturgia católicas ${ }^{9}$.

Pero volvamos a la zarza, que es el objeto principal de este trabajo. Mann le dedica, según dijimos, una atención merecida por su rareza ${ }^{10}$. Con acierto la relaciona con la zarza de Moisés y reconoce lo inusual de su presencia (más tarde nos referiremos a este aspecto). Se sorprende de que la zarza no se haya representado con más frecuencia en escenas de la Encarnación porque la asociación aparece en la liturgia de la Iglesia y en autores marianos del siglo XVI, entre los que cita a Santo Tomás de Villanueva. A pesar de ello considera que son los significados que le dio

\footnotetext{
7 Richard G. Mann, o. c., 75-76.

8 Ibidem, 77.

9 Escribe el beato Orozco: «Mas quando el sacerdote celebra y consagra con aquellas cinco palabras, luego Iesu Christo nuestro Señor está en aquella bendita hostia». En efecto, la presencia de Cristo en la hostia viene aludida en las cinco palabras de la consagración: «Hic est enim corpus meum», y nunca en el Fiat mariano, de lo que se deduce que el estudioso americano no comprendió en absoluto el argumento de Orozco.

10 Richard G. Mann, o. c., 80-82.
} 
fray Alonso de Orozco, al citarla varias veces en sus escritos, los que resultan particularmente relevantes para el programa iconográfico del retablo y, más en concreto, para el lienzo de la Encarnación.

Las afirmaciones que pone en la pluma del beato Orozco y los comentarios que nos merecen son las siguientes:

a) La zarza ardiente «había reaparecido milagrosamente en la habitación de María en el momento de la concepción» (Siete palabras, fol. LVII) ${ }^{11}$. Pensamos que la cita del folio contiene una errata, puesto que se halla dentro del sermón de la cuarta palabra, donde nada se dice respecto de la zarza, y que se trata del folio XLVII, que corresponde a la tercera palabra, es decir, al episodio de la Visitación (Intravit domum Zachariae et salutavit Elisabeth). La mención de la zarza aparece en realidad en XLVII v.: «La çarça de Moysen ardia sin quemarse: siendo nuestra señora madre y juntamente virgen». No cabe duda de que Orozco, que está escribiendo un sermón en el que se refiere una vez más a la Anunciación y Encarnación, recoge una tradicional comparación: como la zarza ardía sin quemarse, María fue madre sin perder la virginidad. Pero ello no significa que esté narrando históricamente el acontecimiento y que afirme que la zarza apareció milagrosamente en la habitación en aquel momento ${ }^{12}$.

b) Era «símbolo del nacimiento de la Virgen» (Siete palabras, fol. LVII v.-LVIII). Y añade que de acuerdo con el Breviario romano. La afirmación puede compartirse si realmente quiso decir nacimiento virginal de Cristo, pero no en otro caso; de cualquier manera la afirmación que aparece en su libro es, literalmente, ridícula. Sobre su referencia al Breviario se tratará después.

c) «Al igual que las hojas de la zarza se mantenían vivas en medio de las llamas, María conservaba la pureza mientras experimentaba el ardor del amor de Dios y la concepción de su Hijo». Aunque no señala la fuente, se sobreentiende que procede del mismo lugar que las anteriores. Sería aceptable esta afirmación si se cambia el término «pureza» por el de «virginidad», pues no son términos equivalentes.

d) Era el «símbolo ideal del voto de castidad al que estaban obligados todos los miembros de órdenes religiosas» (Desposorio espiritual, fol. CCCXIII). Y añade que expresaba la creencia de que la Encarnación había establecido la castidad como requisito indispensable de la vida religiosa, lo que parece una interpretación deducida por Mann de lo anterior. La cita contiene también una errata, pues el Desposorio espiritual abarca del folio CCLXVIII al CCLXXX v. (no existe folio CCCXIII en toda la Recopilación). El folio donde se menciona la zarza es el CCLXXIII v. cuando escribe el beato Orozco sobre «El tercer ornamento del alma es la obediencia» ${ }^{13}$. El agustino dirige esta obra a las monjas y después de referirse a la pobreza y a la

${ }^{11}$ Fray Alonso de Orozco, Obra nueua y muy prouechosa, que tracta de las siete palabras que la virgen sacratissima nuestra Señora hablo, Medina del Campo, 1568 (Francisco del Canto). Existe edición moderna, Madrid 1966 (Rialp); el pasaje que menciona la zarza aparece en la página 120.

${ }_{12}$ Por si sirve de aclaración, copiaremos, sin modificación alguna de transcripción, el párrafo completo: «Y ansi mediante aquella palabra fue obrado en ella el sacramento de piedad: que llama el apostol hablado de la encarnación del hijo de dios: agora con razo se parte el angel Gabriel admirado y alegre: porque sabe que alli estando el presente hizo Dios aquella gran novedad que dixo Hieremias: vna muger cercara al varon fuerte: concibiendo a nuestro Salvador, obro el Spiritu Sancto en aquel instante, concurriendo la madre sanctisima juntamente en aquella formacion del sagrado cuerpo del Señor, fue criado aqlla bienaventurada alma de Christo, vnida aquella humanidad al verbo, la çarça de Moysen ardia sin quemarse: siendo nuestra señora madre y juntamente virgen. Todos estos mysterios se obraron antes que el angel de alli se partiesse y se fuesse a los cielos a dar las nuevas gozosas a los otros spiritus sus hermanos». La cita de San Pablo es I, Tim, 3 , y la de Jeremías, 31, 22. Por cierto que en los dos primeros sermones aparece la misma estampa con representación de la Anunciación, donde no hay zarza alguna.

${ }^{13}$ Fray Alonso de Orozco, Recopilación de las obras, Alcalá de Henares, 1570 (Andrés de Angulo). El Desposorio espiritual en la primera parte, $268-280 \mathrm{v}$. 
castidad trata de la obediencia. Entre sus consideraciones intercala una admonición general sobre la renuncia a los apetitos, recordando que Yaveh mandó a Moisés que se despojara de sus sandalias. Aprovecha también Orozco la imagen de la zarza ardiendo como figura de la vocación y vida religiosa «inflamada de caridad», que arde de amor, y todavía compara las espinas de la zarza con ayunos, disciplinas, cilicios y oraciones ${ }^{14}$. Es claro que no se presenta la zarza como un símbolo del voto de castidad y que, desde luego, la comparación tiene ahora un sentido muy distinto de aquél en que se había empleado respecto a la virginidad de María madre, por lo que nada tiene que ver en relación a la pintura del Greco.

e) Describe la zarza «como el prototipo de la Real Presencia en la Hostia que podía contener a todo el ser divino sin que sufriera daños» (Epistolario, 79-79 v). Añade sin citar fuente alguna que Orozco sostenía «que los sacerdotes debían acercarse al altar con la misma humildad y reverencia con que Moisés se acercara a la zarza». Y de ello deduce Mann que la zarza pintada por el Greco podría «simbolizar el carácter de la milagrosa transformación que se produce cuando el oficiante inicia de nuevo la representación de la Encarnación en la Misa». De nuevo hemos de destacar que la cita es inexacta y que en el lugar señalado del Epistolario no aparece nada en relación a la zarza. Los folios citados corresponden a la «epístola para un señor de vasallos deste reyno» y hacen referencia a los Magos y a la matanza de los inocentes. Pero esta vez resulta más inexplicable la errata. Primero, porque la única mención de la zarza que hemos hallado en el Epistolario está en la página 54 (que en nada se parece a la 79) y corresponde a la carta para los obispos. Además, Orozco no hace símbolo a la zarza de la Sagrada Forma. La carta argumenta que el obispo no puede poner excusas para servir el oficio para el que fue elegido por Dios, pues si lo hace le pasará como a Moisés cuando Yaveh le llamó desde la zarza y dio lugar a la ira divina porque puso excusas a su obediencia ${ }^{15}$. Es evidente que aquí la zarza no es un símbolo, sino una circunstancia de que se sirve el autor para identificar un episodio bíblico que ejemplifica perfectamente las exigencias de la llamada divina. Señalemos, de paso, que la Misa no es una «representación de la Encarnación».

Tras este análisis pormenorizado podemos llegar a algunas conclusiones. La aparición de Yaveh a Moisés en forma de llama en medio de una zarza que ardía pero no se consumía (Ex. 3,2 ) es utilizada por el beato Alonso de Orozco con distintos sentidos en sus comparaciones. En relación al cuadro del Greco que origina este estudio, nos parece evidente que sólo puede interesar el paralelo entre la zarza que no se consumía a pesar de arder y la virginidad de María que no se rompió aunque concibió en su seno como madre. Las demás analogías son, a nuestro juicio, impertinentes respecto a la Encarnación del Greco. Habrá que preguntarse entonces - puesto que Mann considera que el pintor representó ese pasaje y, en concreto, incluyó la zarza en el lienzo por causa de los escritos del fraile agustino- cuáles son las interpretaciones originales de Orozco. Y de los comentarios que hemos hecho se deduce que el beato Alonso no aportó en este punto novedad alguna. Pues la comparación de la zarza ardiendo que no se consumía con la virginidad de María mantenida incluso tras la concepción de Jesús no es ocurrencia suya sino, como Mann reconoce, está en el Breviario y en autores anteriores a Orozco entre los que cita precisamente al también agustino Santo Tomás de Villanueva (Sermones, 306), de quien - de-

14 Transcribimos literalmente el párrafo completo: «Aviso os que estays en tierra sancta y entre gete sancta quitad como mando Dios a Moysen los çapatos de los pies del alma. Dexad essos desseos del siglo, renunciad vuestros appetitos mortiferos que va la vida en ello. De otra arte no os hablara Dios desde la çarça: que arde y no se quema: que es la religión de caridad inflamada (Exod. 3). Cuyas espinas son ayunos, disciplinas, cilicios, oraciones y todo lo demas».

${ }^{15}$ Fray Alonso de Orozco, Epistolario christiano para todos los estados, Alcalá de Henares 1567 (Juan de Villanueva), 54: «Es de temer que el perlado no terna escusa dado que dios le aya elegido si no haze su officio como no la tuvo.. Moysen llamado de Dios a vozes desde la çarça para aquel officio y ansi fue castigado». 
cimos nosotros- pudo conocer textos autógrafos pues sus obras no se publicaron hasta 1572 , cuando ya habían visto la luz todas las que hemos citado del beato Orozco ${ }^{16}$.

Como bien señala Mann, la prefiguración de la virginidad de María en la zarza ardiendo aparece en la liturgia de la octava de Navidad, el 1 de enero, día que también se conmemoraba desde antiguo a María como madre de Dios, según indicaban las oraciones de la Misa. En la tercera antífona de las segundas vísperas se proclama: «Rubum quem viderat Moyses incombustum, conservatam agnovimus tuam laudabilem virginitatem» ${ }^{17}$.

Pensamos que bastaría este canto sagrado para explicar la presencia de la zarza en la pintura del Greco sin tener que recurrir al texto de las Siete palabras de fray Alonso de Orozco, donde no hace sino parafrasearlo. Parece que el autor norteamericano partía del prejuicio de que la iconografía de los lienzos del retablo del colegio de doña María de Aragón tenía que encontrar cabal explicación precisamente en los escritos del beato Orozco. No sólo por haber relegado la antífona citada sino también por haber despachado en poco más de dos líneas de una nota a pie de página una obra tan importante para la cuestión como es la Encarnación de Tiziano en San Salvador de Venecia.

El 7 de mayo de 1559, Antonio Cornovì della Vecchia, rico comerciante establecido en Venecia, encargaba en su testamento a Tiziano «una pala della Incarnation de nostro Signon a colocar en la capilla de San Agustín de la iglesia de San Salvador en un retablo de piedra al que también se refería y que suele atribuirse a Jacopo Sansovino. Cornovì no murió hasta 1572 y lo normal es que se ocupara personalmente de que se cumplieran sus encargos con prontitud; como los frescos por encima del retablo se atribuyen desde el siglo XVII a Francesco Vecellio, fallecido en 1560, cabe pensar que el gran lienzo de su hermano se concluiría cerca de esa fecha, y en cualquier caso antes de 1566 en que lo vio Vasari ${ }^{18}$.

Lo que importa destacar a nuestro propósito es sobre todo que a la derecha, en la zona vertical del escalón superior, figura la siguiente inscripción: IGNIS ARDENS NON/COMBVRENS, alusión precisa a la zarza de Moisés. Exactamente encima del letrero —que la reflectografía reciente ha mostrado originariamente un poco más arriba- se encuentra el jarro de cristal que sirve de soporte, a modo de florero, a algo que sólo puede entenderse como una zarza ardiendo. Si a este hecho unimos la postura de los brazos del ángel cruzados sobre el pecho y la cascada luminosa flanqueada por innumerables ángeles por la que desciende el Espíritu en figura de paloma, no nos ofrece duda - por mucho que existan diferencias de color o composición invertida, entre otras - que el Greco tuvo presente la obra de Tiziano al pintar la suya. Téngase en cuenta que el cretense llegó a Venecia en 1567 (o en 1568) y permaneció allí hasta 1570, por lo que vio el gran lienzo recién pintado y como sensacional novedad hubo de contemplarlo y estudiarlo. Resaltemos además que en el testamento de Cornovì se menciona la pintura como Encarnación y no como Anunciación. Y también que la iglesia era de agustinos, como la de Madrid, aunque no estamos seguros de que tal coincidencia sea trascendente.

Llegados a este punto podemos resumir nuestra exposición de la siguiente forma: el que se establezca una comparación entre la zarza incombusta de Moisés y la permanencia de la vir-

\footnotetext{
${ }^{16}$ Con posterioridad citaremos a Cristóbal de Fonseca, Vida de Christo Señor nuestro, Barcelona, 1597, 119-119 v.: «Inflamada ya la çarça que vio en el monte Moysen no perdiendo la frescura y el verdor de su virginal pureza...». Lo transcribe, sin variantes significativas, Francisco Pacheco, Arte de la Pintura, Sevilla, 1649 (Simón Fajardo); existe edición moderna de Bonaventura Bassegoda i Hugas, Madrid, 1990 (Cátedra), 596.

17 Traducimos: «Como incombusta la zarza que viera Moisés, reconocemos se ha conservado tu loable virginidad».

${ }^{18}$ El estudio más completo y reciente que conocemos sobre la pintura de Tiziano es el de Giovanna Nepi Scirè, Annunciazione (Incarnazione) en Tiziano, Venecia, 1990 (Marsilio Editori), 318-320 y 124-126. No apreciamos las llamas en la estampa del cuadro que grabó Cornelis Cort con la misma claridad que manifiesta esta autora.
} 
ginidad de María tras la concepción de Jesús es doctrina común, pues se encuentra en la liturgia de la octava de Navidad, la utilización de ella por el beato Alonso de Orozco no ofrece particularidad alguna y Tiziano hizo ya aparecer la zarza en un lienzo de la Encarnación que debió servir de inspiración al Greco para su obra. Aquí podría terminar nuestro estudio, pero no es así.

Richard G. Mann afirma haber buscado imágenes en que apareciera la zarza en la escena de la Anunciación sin encontrarlas. La pintura de Tiziano, al parecer, no la conoce directamente y por el tono de su escueta mención es claro que desconfía de que en ella haya una zarza, quizá por no haber visto el cuadro tras la restauración de 1988-1989.

Pero, por nuestra parte, podemos presentar un par de ejemplos que, quizá sorprendentemente, son toledanos y se datan antes y después del retablo para la iglesia del colegio de doña María de Aragón. Ambos son bien conocidos y de pintores importantes, pero no parece que nadie haya reparado en ellos en relación con la zarza ardiendo como prefiguración de la virginidad de María madre.

La primera pintura es una Anunciación de Juan Correa de Vivar (antes de 1510-1566) que se exhibe en el museo del Prado (Fig. 2). Como propuso Isabel Mateo, ha de ser la tabla central del tríptico que contrató en 1559 con fray Alonso de Toledo para el monasterio de jerónimos de Guisando (Ávila), cuya documentación publicó Gómez Menor ${ }^{19}$. En el folio recto del libro abierto que se ve sobre el mueble ante la Virgen, se puede apreciar una estampa, en la que no han reparado quienes se han ocupado de esta pintura, quizá porque en una fotografía es difícil distinguir lo representado. Pero ante el cuadro en el museo del Prado es sencillo observar a Moisés como pastor con ovejas ante la zarza ardiendo en que se ve a Yaveh (Fig. 4).

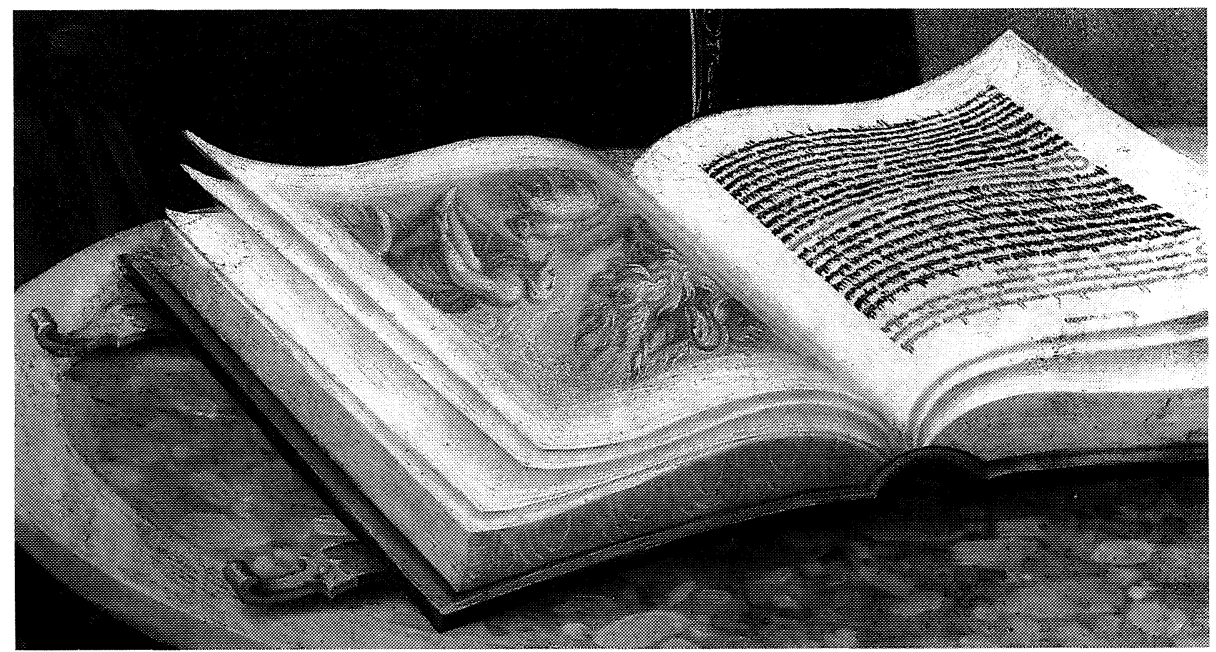

Fig. 4. Juan Correa de Vivar. Anunciación, detalle. Madrid. Museo del Prado.

El otro ejemplo no ofrece la misma claridad y simplicidad, pero en nuestra opinión es también incontestable. Aparece en los frescos del sotocoro de la iglesia del antiguo convento dominico de San Pedro mártir en Toledo, atribuidos tradicionalmente — desde Palomino a Pérez

19 Isabel Mateo Gómez, Tríptico de estación del claustro del monasterio de Jerónimos de Guisando (Ávila), en El Toledo de El Greco, cit., 120-121; Ead., Juan Correa de Vivar, Madrid, 1983 (CSIC), 87-90. 
Sánchez ${ }^{20}$ - a Juan Bautista Maíno (1580-1649), que enmarcaban una talla de la Virgen con el Niño labrada al parecer por Giraldo de Merlo (h. 1574-1620), todavía visible en fotografías antiguas. El 18 de abril de 1613 el convento hizo cuenta final con Giraldo y con Juan de Sevilla de la sillería y de cuatro imágenes: Nuestra Señora de las Nieves del coro, Santo Tomás, Santa Catalina de Siena y Santa Inés de Montepulciano. Por otra parte, recuérdese que Maíno había contratado el 14 de febrero de 1612 la hechura en el plazo de ocho meses de los lienzos del retablo de la iglesia, si bien ya el 29 de enero se le había hecho un pago a cuenta; como profesó en el mismo convento el 23 de julio de 1613 y la Adoración de los Magos está firmada como fraile, es muy posible que esta obra se realizara a partir de esa fecha pero ello no es obstáculo para que los frescos del sotocoro ya estuvieran concluídos en abril de ese año pues se habían terminado las tallas que allí se colocarían. Cabe también la posibilidad de que Maíno pintara los frescos después de profesar, a lo largo de 1613 o incluso en 1614, lo que explicaría que no aparezcan pagos por ellos ${ }^{21}$.

En los frescos de la luneta bajo el coro se representa un gran conjunto de ángeles músicos y cantores, los cuales aparecían también en la Encarnación del $\mathrm{Greco}^{22}$, con otros arrodillados que se dirigen en oración hacia la imagen central, ahora desaparecida, que estaba rodeada por una aureola de querubines pintados. El ángel más cercano a la derecha cruza sus manos sobre el pecho a la manera en que lo hace el arcángel en la pintura del Greco. En el intradós del arco por encima de la luneta se representa en el centro, sobre la imagen desaparecida, la figura del Espíritu

${ }^{20}$ Alfonso E. Pérez Sánchez, Conjunto de frescos de la iglesia de San Pedro Mártir en El Toledo de el Greco, cit., 172-173. Sobre el pintor, Id., Pintura barroca en España. 1600-1750, Madrid, 1992 (Cátedra), 105-108 y la bibliografía citada en 437-438.

${ }^{21}$ Sobre la obra del retablo cfr. Agustín Bustamante García, Juan Muñoz, escultor, «B.S.A.A.» XXXIX (1973), 274. Fernando Marías, Giraldo de Merlo, precisiones documentales, «A.E.A.» 214 (1981), 163-184, puntualizó acerca de sus autores con datos procedentes del libro de la obra de la iglesia , fechó el retablo entre marzo de 1607 en que se firmó la escritura de Juan Muñoz para su hechura y abril de 1611, y las pinturas de Maíno en 1612. Estas fechas son exactas, aunque le faltó decir que Juan Muñoz no intervino personalmente, sino que tan sólo contrató la obra, y quien la realizó fue el ensamblador madrileño Miguel Tomás, que se trasladó a Toledo y cobraba del convento semanalmente cantidades de 50 reales que luego fueron tomadas en consideración en las cuentas con Juan Muñoz, se supone que según un convenio a que llegaron las partes del contrato. Recibió estos pagos desde octubre de 1608 hasta febrero de 1610 y en 24 de abril se ocupaba ya de los colaterales. En febrero de 1610 se hacen los primeros pagos al dorador Gaspar Cerezo, por cuenta también de Muñoz. También se ocupó Marías de la sillería y de las tallas del coro. A proposito de ello precisaremos lo siguiente. Los pagos correspondientes a la sillería se inician en marzo de 1609 y se hicieron a Giraldo de Merlo como contratante de la obra, llevándose cuenta aparte. En el citado libro de la obra de la iglesia, el finiquito de la misma dice: «En 18 de abril de 1613 se hiço la quenta con el señor Giraldo de Merlo y Juan de Sevilla de todas las quentas, dares y tomares de cualesquiera obras que en este convento se an hecho, en particular de las obras de sillería del choro así de demasías como de figuras que el dicho Giraldo de Merlo y Juan de Sevilla an hecho para el dicho choro y como hasta la dicha fecha desta escritura donde entran la imagen de Nuestra Señora de las Niebes del Choro, Sancto Thomás, Santa Catalina de Siena y Santa Inés de Montepulchiano y el camino... para comprar la madera...». El pago de la pintura de Maíno se hizo al margen de cualquiera de los otros dos contratantes, por lo que suponemos que actuó de forma autónoma. La única anotación de pagos al respecto que contiene el libro de la obra es de 29 de enero de 1612 y dice que en esa fecha se le dieron 200 ducados a cuenta de la pintura. Luego dejaría de cobrar, al ingresar como fraile en el convento. En 16 de junio se registra un pago de 165 reales por la compra de quince varas de manteles alemaniscos para la pintura del retablo; no sabemos con certeza si eran para los lienzos (A.H.N., Clero, libro 15.228).

${ }_{22}$ Aunque no es nuestro propósito señalar cada uno de los pasajes de fray Alonso de Orozco que Mann no ha entendido o ha tergiversado para intentar demostrar que el Greco se inspiró en sus escritos al pintar los lienzos del retablo de la iglesia del Colegio de doña María de Aragón, sucumbimos de nuevo a la tentación al recordar que el autor norteamericano comenta que no solían aparecer ángeles músicos en las pinturas de Anunciación y Encarnación y que los puestos por el Greco se inspiraron «muy probablemente» en la descripción de fray Alonso. Y añade: «Según el fraile, un ángel comenzaba a cantar en el momento de la concepción y otros le respondían de inmediato cantando y tocando instrumentos hasta que los cielos se llenaban pronto de su música». El texto de las Siete palabras en el sermón tercero, dice en realidad lo siguiente: «Y si en naciendo el Redendor, un ángel comenzó a cantar: Gloria a Dios y paz a los hombres, y luego muchos le respondieron cantando el mismo cántico: ¿por qué aquí en este glorioso día, cuando Dios se hizo Hombre, no habían los ángeles de hacer grandes alegrías y cantar el mismo cántico?» (ed. 1966, 119). 
Santo en forma de paloma y, flanqueándola, las de Moisés con la tabla de la Ley en la mano (Ex., 31, 18) y un ángel sosteniendo el mástil con la serpiente de bronce (Núm., 21, 9), y Aarón con un incensario en la mano (Núm., 17, 11-12) y vara florecida en la otra (Núm., 17, 23-26); como cuadros fingidos sobre el primero está pintado el episodio de la aparición de Yaveh en la zarza ardiendo ante Moisés genuflecto con rebaño al fondo (Ex., 3, 1-3) y sobre el segundo el consejo de Moisés a Aarón tras el motín del pueblo y la aparición de la nube (Núm., 17, 6-11).

El planteamiento iconográfico de los lienzos del retablo mayor se completa a nuestro entender con los frescos del sotocoro, como conjunto del mismo autor. Tras el altar se representaban las cuatro pascuas: Navidad (Adoración de los pastores), Epifanía (Adoración de los Magos) incluida litúrgicamente dentro del tiempo de Navidad, Resurrección y Pentecostés (con sendos lienzos de los asuntos correspondientes). En el coro aparecía como el origen de todo ese programa de salvación, la imagen de María con el Niño, maternidad divina, cuya concepción virginal viene aludida por el episodio de la zarza de Moisés; la representación de la rama seca de Aarón, que floreció en la tienda del Testimonio entre las de los demás representantes de las familias de Israel, es también figura de la Virgen concibiendo sin intervención de varón. Las otras imágenes de aquellos patriarcas, la de Moisés levantando la serpiente y la de Aarón con el incensario, tienen relación, en cambio, con la acción salvadora de Cristo a través de su crucifixión (Jn, 3, 14-15: «Y como Moisés levantó la serpiente en el desierto así tiene que ser levantado el Hijo del hombre para que todo el que crea tenga por Él vida eterna») y su muerte (expiación representada en el incienso que esparció Aarón, según el aviso de Moisés, sobre su pueblo atacado por la plaga).

Contamos, por tanto, con tres ejemplares pintados en Toledo - por Correa (1559), el Greco (1597-1600) y Maíno (1613-1614) — de la zarza ardiendo como prefiguración de María a la vez virgen y madre. Las obras fueron hechas para jerónimos, agustinos y dominicos respectivamente, por lo que no cabe pensar en que se tratara de peculiaridad exclusiva en la interpretación bíblica de una sola orden o de alguno de sus doctores; pero, al mismo tiempo, hay que suponer que hubo en los tres casos unos inspiradores de garantía en cuanto a sus conocimientos de $\mathrm{Sa}$ gradas Escrituras.

Que las tres obras se hicieran en Toledo obliga a investigar si existe en relación a la ciudad alguna razón específica que motive la presencia de la zarza en relación a la Encarnación de Cristo en María. Pero al mismo tiempo, la pintura de Tiziano que antes citamos demuestra que el asunto no fue exclusivo de Toledo. Así las cosas, presentaremos algunos textos para procurar que la cuestión quede más clara.

San Ildefonso (607-667), arzobispo de Toledo desde 657, escribió De virginitate perpetua Sanctae Mariae, pero en esta obra principal no utiliza el símbolo de la zarza ardiendo, aunque como el título de la obra indica se refiera a la virginidad de María a pesar de la concepción de Jesús. Véase este párrafo: «Cum conceptu virgo, per conceptum virgo, in conceptu virgo, post conceptum virgo, per partum virgo, in partu virgo, cum partu virgo, post partum virgo» ${ }^{23}$. San Bernardo (1091-1153) escribió una homilía sobre las palabras del evangelio: «Fue enviado el ángel Gabriel» y en este texto sí hay referencia a la zarza: «¿Qué pronosticaba en otro tiempo aquella zarza de Moisés, echando llamas pero sin consumirse, sino a María dando a luz sin sentir dolor?». Parece claro que el sentido de la última frase es el mismo que venimos proclamando. Conviene advertir que, a continuación, San Bernardo se refiere a la vara de Aarón, de manera

${ }^{23}$ San Ildefonso, De virginitate perpetua sanctae Mariae, I; se conservan manuscritos desde el siglo Ix. Hemos manejado la edición de Vicente Blanco García, Madrid, 1977 (Centro de Estudios Históricos). 
que van seguidas las dos prefiguraciones utilizadas por Maíno ${ }^{24}$. Y también que esta homilía es citada varias veces por fray Alonso de Orozco.

El catecismo que mandó publicar San Pío V según el concilio de Trento en 1566 y del que hubo traducción castellana en $1583^{25}$, en el epígrafe titulado «Con qué figuras y profecías fueron principalmente representados los misterios de la concepción y natividad de Cristo» afirma lo siguiente: «Siendo grandes y muchísimos los misterios de esta admirable concepción y nacimiento, plugo a la divina Providencia anunciarlos con muchas figuras y profecías. Por eso entendieron los Santos Padres que pertenecían a este objeto muchos pasajes que leemos en varios lugares de la Sagrada Escritura, y especialmente... y la zarza que vio Moisés arder sin consumirse («et rubum quem Moyses vidit ardere et non comburi». Exod. III, 2)».

$\mathrm{Si}$ a esto unimos el texto litúrgico de la octava de Navidad que recogimos al comienzo de este trabajo, resulta claro que la prefiguración de la perpetua virginidad de María en la zarza ardiendo era común en la doctrina y en la liturgia católicas, por lo que queda justificada su utilización tanto por Tiziano como por los pintores que lo hicieron en Toledo. Aunque es evidente también que la inmensa mayoría de las representaciones que se hicieron de la Anunciación y de la Encarnación no incluyeron la zarza, porque establecer tal comparación simbólica no tenía que ser objeto principal ni siquiera secundario de aquellos asuntos.

Pero el hecho de que aparezcan tres ejemplos toledanos en un espacio de tiempo poco superior al medio siglo, y uno de ellos anterior al catecismo de San Pío V, puede tener una explicación que refuerce la general válida para todo el orbe católico en especial tras la celebración del concilio de Trento. El X concilio de Toledo, que se inauguró el 1 de octubre del 656, fue general, aunque no asistieron muchos obispos, porque en su programa figuraba la introducción de una importante novedad en el calendario litúrgico de la Iglesia hispana. El primer canon aprobado se titula «De celebritate festivitatis Dominicae Matris» y por él se decretó que, como en la fecha del 25 de marzo en que se conmemoraba la Anunciación de la Virgen tomando como referencia la de la Natividad del Señor, no cabía una celebración digna por impedirlo la Cuaresma o la pascua de Resurrección, se trasladara al 18 de diciembre, o sea, una semana antes de la Natividad ${ }^{26}$. Esta fiesta vino a llamarse después de la expectación del Parto de la bienaventurada Virgen María. Pero precisamente el 18 de diciembre la antífona mayor del oficio litúrgico dice: «O Adonai, et dux domus Israel, qui Moysi in igne flammae rubi apparuisti et ei in Sina legem dedisti: veni ad redimendum nos in brachio extento» ${ }^{27}$. Así vinieron a unirse la celebración de la Encarnación de Cristo en María con el deseo ardiente de la llegada del Salvador, y la mención de la zarza, que en la antífona se refiere a la aparición de Dios a Moisés cobró la nueva dimensión mariana por contigüidad. Clérigos y religiosos que recitaban esta antífona en la fiesta de la Anunciación - y también la de la octava de Navidad ya citada - tendrían muy presente su carácter de prefiguración de la perpetua virginidad de María, y no se olvide que los tres encargos toledanos fue-

\footnotetext{
24 San Bernardo, Homilia super «Missus est». Recogida y traducida en La Virgen madre, Madrid, 1987 (Rialp), 37.

${ }^{25}$ Catecismo según el decreto del concilio de Trento mandado publicar por San Pío V, pontífice máximo, y después por Clemente XIII, Madrid, 1901 (Gregorio del Amo) y reproducido, Madrid, 1972 (Editorial Magisterio Español), parte primera, cap. IV, 10, p. 46. Recogemos aquí, por expresar de modo oficial la doctrina católica al respecto, la explicación al tercer artículo del Credo (Qui conceptus est de Spiritu Sancto, natus ex Maria Virgine): «al modo que los rayos del Sol atraviesan la substancia densa del vidrio sin quebrarle ni hace en él la menor lesión, así, digo, y por modo más sublime, Jesucristo salió del seno materno sin detrimento alguno de la virginidad de su Madre; así pues, con alabanzas muy verdaderas, celebramos su inmaculada y perpetua virginidad. Y esto, en verdad, se obró por virtud del Espíritu Santo, que tanto engrandeció a la Madre a la concepción y en el nacimiento de su Hijo que le dio fecundidad y conservó su perpetua virginidad».

${ }^{26}$ José Orlandis y Domingo Ramos-Lissón, Historia de los concilios de la España romana y visigoda, Pamplona, 1986 (EUNSA), 361-363.

${ }^{27}$ Traducimos: « $\mathrm{O}$ Oh Adonai y jefe de la casa de Israel que apareciste a Moisés en el fuego de la zarza encendida y le diste la ley en el Sinaí, ven a redimirnos con el brazo extendido!».
} 
ron para monasterios o conventos y hechos por religiosos o sacerdotes ${ }^{28}$ De paso, resaltaremos que la antífona mayor del 18 de diciembre explica exactamente la doble representación que hace Maíno de Moisés con la tabla de la ley y en la escena de la aparición de Yaveh en la zarza, y al reunir las figuras de Moisés y de la Virgen demuestra su inspiración en la celebración de la fiesta de la Virgen trasladada al 18 de diciembre.

En conclusión, la zarza ardiendo sin consumirse es utilizada como prefiguración de la virginidad de María madre de Cristo en la doctrina y liturgia católicas en general, y de modo especial es resaltada dentro del ámbito eclesiástico toledano por la doble conmemoración de la Encarnación en 25 de marzo y 18 de diciembre, decidida en Concilio allí celebrado, lo que nos hace tomar una postura contraria a vincular la explicación de esta imagen a un autor determinado.

${ }^{28}$ El origen de este artículo fue una conferencia pronunciada en el Museo Casa del Greco de Toledo que llevó el mismo título que el presente trabajo. Al terminar la conferencia, uno de los asistentes a la misma se acercó para manifestarnos que, en su niñez, cantaban un villancico que contenía una estrofa en que se terminaba: «y la zarza ardía, y la zarza ardía y no se quemaba la Virgen María», lo que supone un testimonio de la persistencia de esta imagen en la zona de Toledo. 